\title{
The role of chemokines in intestinal inflammation and cancer
}

\author{
Dingzhi Wang ${ }^{1}$, Raymond N. DuBois ${ }^{1}$, and Ann Richmond $2,3,{ }^{*}$ \\ ${ }^{1}$ Department of Cancer Biology, MD Anderson Cancer Center, The University of Texas, Houston, \\ TX 77030-4009 \\ ${ }^{2}$ Department of Veterans Affairs, Nashville, TN, 37212 \\ ${ }^{3}$ Department of Cancer Biology, Vanderbilt University School of Medicine, Nashville, TN 37232
}

\begin{abstract}
Chronic inflammation is a risk factor for several gastrointestinal malignancies, including colorectal cancer. Recent epidemiologic studies and clinical trials demonstrate that long-term use of nonsteroidal anti-inflammatory drugs (NSAIDs) markedly reduced the relative risk of colorectal cancer. Chronic inflammation associated with development of cancer is in part driven by the chemokine system. Chemokines are chemoattractant cytokines that recruit leukocytes from the circulatory system to local inflammatory sites. In this review, we highlight recent breakthroughs in our understanding of the role of chemokines in inflammatory bowel disease and colorectal cancer from animal models and human studies. These findings provide a rationale for the development of new anti-inflammatory therapeutic approaches for prevention and/or treatment of inflammatory bowel disease and colorectal cancer.
\end{abstract}

\section{Introduction}

Chronic inflammation caused by infections or autoimmune diseases is clearly associated with increased cancer risk in a number of instances. For example, it has been long known that patients with persistent hepatitis B, Helicobacter pylori infections, or an immune disorder such as ulcerative colitis have higher risk for the development of liver or gastrointestinal tract cancer. It has been estimated that chronic inflammation contributes to the development of approximately $15 \%$ of malignancies worldwide [1]. The best evidence for the link between inflammation and tumor progression comes from recent epidemiologic studies and clinical trials showing that long-term use of non-steroidal anti-inflammatory drugs (NSAIDs) reduced the relative risk of developing colorectal cancer (CRC) by 40-50\% [2].

Despite epidemiological and experimental evidence strongly implicating chronic inflammation as a risk factor for CRC, surprisingly little research has directly addressed the question of how chronic inflammation results in neoplastic transformation and progression. It is generally thought that chronic inflammation orchestrates a tumor-supporting microenvironment that promotes tumor initiation, progression, angiogenesis, and metastasis. Together with the hereditary syndromes of Familial Adenomatous Polyposis and hereditary non-polyposis CRC,

\footnotetext{
*Correspondence to: Ann Richmond, Ph. D., Ingram Professor and Vice Chair, Department of Cancer Biology, 432 Preston Research Building, VA Senior Research Career Scientist, Vanderbilt University School of Medicine, Nashville, TN 37232, Tel: 615-343-7777, ann.richmond@Vanderbilt.edu.

Publisher's Disclaimer: This is a PDF file of an unedited manuscript that has been accepted for publication. As a service to our customers we are providing this early version of the manuscript. The manuscript will undergo copyediting, typesetting, and review of the resulting proof before it is published in its final citable form. Please note that during the production process errors may be discovered which could affect the content, and all legal disclaimers that apply to the journal pertain.
} 
IBD is among the top three high-risk conditions for CRC. Moreover, chronic IBD (especially pan-colitis) significantly increases the risk of developing CRC [3,4].

The gastrointestinal mucosa forms a complex, semi-permeable barrier between the host and the largest source of foreign antigens. The healthy gastrointestinal mucosa is the largest repository of immune cells within the human body. The constitutive presence and trafficking of immune cells into the mucosal compartment has been termed physiologic inflammation.

The mucosal immune system has the ability to mount an immune response to pathogens while maintaining tolerance to the vast array of benign luminal antigens from food and commensal bacteria. Many inflammatory processes are self-limiting, supporting the existence of endogenous anti-inflammatory mechanisms. An abnormal mucosal immune response is thought to result in chronic inflammation and development of inflammatory bowel disease (IBD). IBD in humans is a complex class of disorders that has been grouped into two major forms, ulcerative colitis (UC) and Crohn's disease (CD). These chronic conditions of the gut ordinarily affect over 5 million people between the age of 16 and 40 and can cause significant morbidity in North American and Europe. In general, $\mathrm{CD}$ has been traditionally considered to be Th1 (T helper) cell-mediated response, while UC is thought to be Th2 T-mediated response. However, a newly defined class of IL-17-producing $\mathrm{CD} 4^{+} \mathrm{T}$ cells, termed Th17, has been found to play a key role in CD and may alter the notion of this Th1 and Th2 dichotomy in IBD [5, 6]. The common pathological changes associated with IBD include increased massive infiltration of deregulated immune cells, production of pro-inflammatory mediators including cytokines and chemokines, diminished epithelial barrier integrity, and/or a deficient feedback system that normally down-regulates the mucosal response to luminal factors [7-9]. In response to inflammation, tissue-resident immune cells locally secrete cytokines, chemokines, matrixremodeling proteins, and other bioactive mediators that recruit additional leukocytes from the circulation into the tissue which in turn causes intestinal damage by the release of cytokines and proteolytic enzymes. Disruption of epithelial barrier further results in activation of resident inflammatory cells by microbial invaders or endogenous chemokine ligands. Therefore, chemokines are believed to be key mediators in this process of aberrant leukocyte recruitment during intestinal injury, inflammation, wound repair, and cancer.

Chemokines have emerged as essential immune molecules in the pathogenesis of IBD and CRC. Chemokines are a group of chemoattractant cytokines that play an essential role in the recruitment of leukocytes from the circulation system to local inflammatory sites. Over 50 chemokines have been identified and are classified into four subfamilies--C, CC, CXC, CX3C-based on the position of the first two highly conserved cysteines residues in the amino-terminus of the protein (Table 1). The CXC chemokines can be further classified into ELR ${ }^{+}$and ELR chemokines based on the presence or absence of the motif 'glu-leu-arg' (ELR motif) preceding the CXC sequence. Chemokines exert their biological functions via binding to their cognate receptors, which are G-protein-coupled receptors. Only 20 chemokine receptors have been discovered so far (Table 1). There is considerable redundancy of biological function in this chemokine network. The expression profile of chemokines and their receptors generally correlates with the numbers and types of infiltrating leukocytes in IBD and CRC.

\section{Chemokines and IBD}

IBD is believed to arise out of fundamental dysregulation of the immune system in response to environmental triggers. The main pathological feature of IBD is characterized by a massive infiltration of neutrophils, lymphocytes, and monocytes in the inflamed tissues of the intestine. Inflamed tissues in IBD are known to be associated with changes in leukocyte profiles as well as their functionality. For example, studies suggest that the normal intestinal macrophages can't be easily induced to mediate acute inflammatory responses. However, there is an increased infiltration of dysregulated macrophages derived from circulating monocytes, into the mucosa 
of active IBD. These recruited macrophages are phenotypically different from the resident population of cells and play a major role in the chronic mucosal inflammation by secreting many proinflammatory cytokines, such as IL-1, IL-6, IL-12, IL-18, IL-8 (CXCL8), and $\mathrm{TNF} \alpha[10]$. Elevation of proinflammatory chemokines and leukocyte infiltration are observed in the intestinal mucosa of IBD patients and this elevation strongly correlates with the grade of disease [11,12].

\section{ELR ${ }^{+}$CXC chemokines}

$\mathrm{ELR}^{+} \mathrm{CXC}$ chemokines play an important role not only in activation and recruitment of neutrophils, but also in induction of exaggerated angiogenesis at sites of inflammation. The levels of chemokines that attract neutrophils, MGSA/Gro $\alpha$ (CXCL1), ENA-78 (CXCL5), GCP2 (CXCL6), and IL-8 (CXCL8), are positively correlated with the inflammatory state in IBD patients [13-15]. CXCL5 is preferentially expressed in epithelial cells of the intestinal mucosa of patients with IBD [16], while CXCL6 is highly expressed in endothelial cells in the inflamed tissue of IBD patients [17]. CXCL1 in the serum is significantly elevated in the IBD patients [13]. Importantly, the serum level of CXCL1 is highly correlated with the grade of disease and is reduced after initiation of therapy, indicating that CXCL1 might be used as a biomarker of IBD [18]. The essential role of neutrophils in angiogenesis was demonstrated in neutropenic mice (mice treated with anti-Gr-1 antibody) where CXCL1, CXCL2 and CXCL8 failed to induce angiogenesis [19]. Clotrimazole suppressed intestinal inflammation and angiogenesis through down-regulation of CXCL8 in a trinitrobenzene sulfonic acid (TNBS)induced rat colitis model [20]. These data support the notion that CXCL8 enhances inflammation through recruitment of neutrophils and promotion of angiogenesis. Clotrimazole is an antifungal medication commonly used in the treatment of fungal infections of both humans and animals such as vaginal yeast infections and ringworm. It is also used to treat athlete's foot and fungal infection of the groin (tinea cruris), but is not used clinically for IBD. In addition, neutrophils produce several pro-angiogenic cytokines including CXCL1 and CXCL8[19,21]. Neutrophils also produce MMP-9 which stimulates the release of the angiogenic factor VEGF from matrix proteins[22]. Inflammation-induced blood vessel formation in turn allows the rapid influx of nutrients and inflammatory cells into the bowel.

\section{ELR- CXC chemokines}

The CXCR3 ligands, Mig (CXCL9), IP10 (CXCL10), and CXCL1, which primarily attract activated Th1 T cells and natural killer cells (NK), are involved in CD. NK cells have been shown to be involved in the differentiation of naive $\mathrm{CD} 4^{+} \mathrm{T}$ cells into Th1 cells [23]. Although levels of these chemokines in serum and tissues are elevated in CD patients [24], the role of these chemokines in disease severity, susceptibility, and progression is not certain. However, the evidence that deletion of CXCL10 attenuates colitis in IL-10 ${ }^{-/-}$mice [25] supports the concept that this chemokine plays an important role in IBD. IL-10/- mice spontaneously develop IBD with a Th1-polarized cytokine pattern.

Other ELR- CXC chemokines such as SR-PSOX/scavenger receptor for phosphatidyl-serine and oxidized lipoprotein (CXCL16) are also elevated in serum and tissues of active CD patients [26]. In an experimental model for IBD, both SDF-1 (CXCL12) and its receptor CXCR4 are significantly increased in mice with dextran sulfate sodium (DSS)-induced colitis and a CXCR4 antagonist reduces inflammation in DSS-treated mice and IL-10 $10^{-/-}$mice [27], suggesting that the CXCL12/CXCR4 axis play a role in IBD. There is no report thus far on the participation of BCA-1 (CXCL13) and BRAK/bolekine (CXCL14) in IBD. 


\section{CC chemokines}

The levels and distribution patterns of CC chemokines in IBD have been summarized in a recent review article [28]. Therefore, we will mainly discuss the role of these chemokines in animal models of IBD.

Monocytes/Macrophages, T cells and NK cells-Monocytes, which differentiate into macrophages, migrate to inflammatory sites in response to an array of pro-inflammatory $\mathrm{CC}$ chemokines including MCP-1 (CCL2), MIP1 $\alpha$ (CCL3), MIP-1 $\beta$ (CCL4), RANTES (CCL5), MCP-4 (CCL13), HCC1 (CCL14), HCC2 (CCL15), HCC4 (CCL16). In addition, these chemokines also attract NK cells, T cells, and immature dendritic cells (DC). CCL2 deficient mice show a significant reduction in the severity of colitis in hapten-induced experimental colitis [29] and deletion of its receptor, CCR2, protects mice from DSS-induced colitis [30], suggesting that the CCL2-CCR2 signaling plays an important role in IBD. Furthermore, the evidence that CCR5-deficient mice are resistant to DSS-induced colitis supports the notion that CCR5 ligands, CCL3, CCL4, and CCL5, are involved in the progression of IBD [30]. The observation that simultaneous blockade of CCR2, CCR5, and CXCR3 by antagonists protect mice from DSS-mediated colitis indicates that the antagonists of these receptors may be considered as potential drugs for IBD treatment [31]. Deletion of CCR6 disrupts the formation of normal lymphoid structures [32]. Thus, it is conceivable that inhibition of CCR6 may abrogate chronic intestinal inflammation through suppression of gut-associated lymphoid tissue. In addition, neutralization of TECK (CCL25)/CCR9 by their antibodies ameliorates early but not late chronic murine ileitis in a spontaneous murine model of chronic ileitis [33]. Thus, multiple chemokine receptors (CCR2, CCR5, CCR6, CCR9 and CXCR3) are potential therapeutic targets for treatment of IBD.

Regulatory $\mathrm{T}$ cells ( $\mathrm{T}$ regs), which inhibit the autoimmune response, are a subset of $\mathrm{CD}^{+} \mathrm{T}$ cells. In a mouse adoptive transfer model of IBD, T reg cells are capable of preventing the development of colitis while CCR4-deficient $\mathrm{T}$ reg cells failed to suppress the development of colitis by being unable to inhibit the generation of pathogenic $\mathrm{T}$ cells after adoptive transfer, indicating that CCR4 and its ligands TARC (CCL17) and MDC/STCP-1 (CCL22) play an important role in T-reg suppressive function in vivo [34]. Similarly, CCR7 KO T-regs have an approximately two-fold reduced capacity to protect the development of colitis by failing to control the proliferation of CD4 T cells in a transfer model of IBD [35]. Since T and B cells play a crucial role in IBD progression, blockade of T- and B-cell-activation by either antibodies or small molecules is currently under evaluation in phase I-III clinical trials for treatment of IBD [36].

Eosinophils-Eosinophils are involved in the initiation and propagation of inflammatory reactions, inducing tissue damage and dysfunction [37]. CC chemokines such as CCL5, MCP2 (CCL8), eotaxin-1 (CCL11), eotaxin-2 (CCL24), and eotaxin-3 (CCL26) have been shown to recruit eosinophils into inflammatory sites. Recently, Hogan's group reported that eosinophildeficient mice were resistant to DSS treatment and they also found that intestinal macrophage and epithelial cell-derived CCL11 mediates eosinophil recruitment and function in pediatric ulcerative colitis [38].

Dendritic cells-MIP3 $\alpha /$ LARC/exodus-1 (CCL20) is primarily produced by the gut epithelium, which attracts dendritic cells expressing its receptor, CCR6. CCL20 mRNA is higher in human inflammatory colonic lesions than the matched non-inflamed tissues [39], while CCR6 knockout mice exhibited less severe chronic inflammation than wild-type mice in a DSS-treated model [40]. 


\section{Chemokines and CRC}

During hereditary and sporadic colon carcinogenesis, transformed colonic epithelial cells are able to secret cytokines and chemokines that recruit and re-program various types of proinflammatory leukocytes and endothelial cells to establish a tumor promoting microenvironment. The tumor favoring microenvironment releases additional angiogenic factors, mitogens, proteolytic enzymes, and chemokines producing the "cytokine storm". This ultimately results in recruitment of more inflammatory cells which facilitate tumor-associated angiogenesis and metastasis.

Chemokines are also identified as potential regulators of tumor cell transformation, growth, angiogenesis, and metastasis. The role of chemokines and their receptors in CRC has been studied only in very recent years, although their functions have been intensively investigated in many other types of cancers [41]. Tumor associated leukocytes recruited and activated by chemokines play an important role in enhancing growth and spread of malignancy by inducing angiogenesis and controlling tumor cell migration/invasion [42]. In addition to their function as chemoattractants for leukocytes, chemokines also induce epithelial cell migration and endothelial cell migration and endothelial tube formation by directly acting on these cells that express chemokine receptors [41]. The levels of pro-inflammatory chemokines such CCL2, CCL3, CCL4, and CCL5, and pro-angiogenic chemokines such as CXCL1, CXCL5, and CXCL8 are elevated in human colon tumor tissues as compared to the matched normal tissues [43], indicating that these chemokines and their receptors play an important role in regulating colon tumor progression, angiogenesis, and metastasis. The timing of expression of these chemokines during tumor progression may be very important. For example, one study reported that when CXCL5 levels are low in human CRC, there are reduced numbers of CD8+ T cells and poor prognosis [44]. In a study of resected colorectal adenoma, colorectal carcinoma, and their respective metastatic lesions in the liver, CXCL1 and CXCL5 were identified to have a role in the progression from colorectal adenoma to colorectal cancer, with CXCL1 levels being higher in CRC and CXCL5 being highly over expressed in colorectal liver metastases [45]. Moreover, CXCL8 has been identified as one of the three central genes (CXCL8, desmin and enolase) that comprise a network specific to colon cancer [46]. The elevated expression of CXC chemokines in colorectal cells is often the result of activation of an oncogene in the epithelial cells, but tumor progression only occurs when this is accompanied by loss of a tumor suppressor, such as p16 ${ }^{\text {INK4A }}$. For example, expression of both CXCL8 and IL-6 is elevated in oncogene induced senescent colorectal cells that express the tumor suppressor, p16 ${ }^{\text {INK4a }}$. Thus, it is important to understand the gene expression profile in the context of elevation in expression of CXC chemokines when predicting their role in CRC progression [47]. In contrast, when an oncogene is expressed and CXCL8 and IL-6 expression are elevated, but p16 $6^{\mathrm{INK} 4 \mathrm{a}}$ is deleted, tumor progression will occur. However, elevated expression of chemokines is not always associated with enhanced tumor progression or tumor growth, since reduced CCL2 expression was shown to be associated with poor prognosis in an analysis of 101 colorectal cancer patients post surgical resection [48]. Moreover, 6Ckine/SLC/exodus-2 (CCL21) and MEC (CCL28) are highly expressed in normal colon mucosa, but are ubiquitously lost in most human CRC $[49,50]$. These data are in agreement with the concept that early recruitment of M1 macrophages can antagonize tumor progression [51,52].

\section{Tumor Metastasis}

Clinical studies suggest that the levels of CXCR3, CXCR4, and CCR7 in primary CRC significantly correlate with recurrence, survival, lymph node and liver metastasis [53-58]. Moreover, polymorphisms in CXCL8 are associated with risk of recurrence in stage III colon cancer patients [59]. On the other hand, the high expression of fractalkine (CX3CL1) is correlated with a better prognosis for CRC patients [60]. Furthermore, CXCR4 and CCR6 
expression are significantly elevated in colorectal cancer cells that metastasize to the liver and the expression of the CCR6 ligand, CCL20, is high in the liver, suggesting that CCL20 may contribute to the selective recruitment of CCR6-expressing cancer cells into the liver [61]. Studies using cell culture systems indicate that the CXCR3 ligand CXCL10, the CXCR4 ligand CXCL12, as well as CXCR2 ligands CXCL1, CXCL2 and CXCL8 stimulate colon carcinoma cell migration/invasion, respectively [54,62-64]. CXCL8 may mediate TNF $\alpha / T G F \beta$-driven epithelial-mesenchymal transition in colonic carcinoma cells [65]. Importantly, when rectal transplantation xenografts of CXCR3-expressing CRCs were developed in nude mice, cells migrated to lymph nodes and the metastatic lesions that formed grew more rapidly than did CXCR3 negative transplanted tumors, indicating that the CXCR3 signaling plays a essential role in tumor cell migration into metastatic sites [56]. Moreover, CXCR4 is also required for the metastatic spread of a CRC cell lines to liver and lung in mice [66]. In contrast, CX3CL1 inhibited the growth of a colon tumor cell line in skin, liver, and lung in the standard subcutaneous model and in two orthotopic models of metastatic colon cancer (liver and lung) [67]. The question before us now is "Do these receptors modulate tumor cell migration and invasion in spontaneous animal models?" In a spontaneous mouse model (cis-Apc/Smad4), only CCL9 was elevated in tumor epithelium while loss of CCR1, the receptor for CCL9, significantly suppressed tumor invasion into the smooth muscle layer in this model [68], suggesting that CCL9-CCR1 signaling axis plays an important role in colon tumor metastasis.

\section{Tumor growth}

There are limited reports concerning the functions of chemokines in regulating tumor growth. Expression and genetic polymorphisms of CXCL5 are positively associated with tumor growth in colorectal cancer patients [69]. CCL2, a potent macrophage chemoattractant, is associated with the accumulation of associated macrophages and CRC progression [70]. In cell culture system, CXCL8 induced cell proliferation and migration through metalloproteinase-cleavage pro-HB-EGF in human colon carcinoma cells [71]. SDF-1 (CXCL12) promoted colon carcinoma cell proliferation via CXCR7, but not CXCR4 [72]. This finding indicates that CXCL12 regulates tumor cell proliferation and migration/invasion via its two different receptors. CCL20 also induced colon tumor cell proliferation via CCR6 [39]. In tumor implantation models, MGSA $\beta /$ gro $\beta$ (CXCL2) accelerated tumor growth by inducing tumor cell proliferation when colorectal cancer cells were implanted in dorsal skin fold chambers of syngeneic BALB/c mice [73]. Interestingly, CXCL13 promoted colon carcinoma cell growth in the liver via its receptor CXCR5 in an orthotopic model of metastatic colon cancer [74]. Although CXCL12 was shown to induce tumor cell migration and invasion, treatment of CXCL12 suppressed the growth of preexisting tumors and induced accumulation of dendritic cells and $\mathrm{CD}^{+}$cells in the tumor in the standard subcutaneous model, indicating that CXCL12 inhibits tumor growth through attracting dendritic cells to the tumor [75]. A similar observation was made in the treatment of preexisting tumor with CX3CL1 [76]. Over-expression of CCL21 reduced tumor growth in the mouse $\mathrm{C} 26$ colon tumor model [77]. In addition, intra-tumoral injection of recombinant adenovirus encoding CCL17, CCL19, CCL21, and lymphotactin (XCL1) induced tumor regression in the mouse CT26 colon tumor model through activation of antitumor immunity, respectively [78-81].

\section{Tumor angiogenesis}

It has been well established that ELR ${ }^{+}$chemokines including CXCL1, CXCL2, (MGSA $\gamma /$ gro (CXCL3), CXCL5, CXCL6, NAP-2 (CXCL7), and CXCL8 enhance angiogenesis by directly activating CXCR2 on endothelial cells, while ELR ${ }^{-}$chemokines such as CXCL9, CXCL10, and ITAC (CXCL11) are angiostatic factors [82]. CXCL1 is highly expressed in human colorectal tumors and mediates the effects of COX-2 derived $\mathrm{PGE}_{2}$-induced angiogenesis in CRC $[83,84]$. CXCL2 treatment of colon tumor cells implanted in the liver lobe of mice promoted angiogenesis and tumor growth [57]. Moreover, blockage of the 
CXCL12/CXCR4 signaling axis inhibited tumor growth through the suppression of tumorassociated angiogenesis in the standard subcutaneous model [85]. The CC chemokine, CCL2, has been shown to indirectly stimulate tumor angiogenesis through induction of VEGF release in human macrophages via a COX-2/PGE2 pathway [86]. In contrast, treatment of pre-existing tumors with either CXCL9 or CXCL10 combined with low dose cisplatin significantly suppressed tumor growth and angiogenesis in the mouse CT26 colon tumor model $[87,88]$.

\section{Conclusions}

Leukocyte infiltration is a common pathological feature of IBD and almost all cancers including CRC. Chemokines are generally responsible for recruiting inflammatory cells into the mucosal of inflamed intestine and they appear to play the similar role in attracting immune cells into the tumor to shift antitumor to pro-tumor microenvironment. Recently, the role of chemokines and their receptors has been investigated in the pathogenesis of IBD and CRC. Emerging evidence demonstrates that some chemokines promote inflammatory microenvironment in IBD and CRC. This tumor-supporting microenvironment further results in the progression of IBD and promotes tumor initiation, progression, angiogenesis, and metastasis. Other chemokines suppress tumor growth through promoting antitumor immunity. In addition to regulation of the tumor microenvironment, chemokines have a direct effect on epithelial cells that express chemokine receptors, which can potentially induce epithelial cell transformation, proliferation, and migration/invasion. Studies on the biological functions of chemokines in IBD, a model of colonic inflammation, might also help us further our knowledge of the process by which inflammation may cause or promote CRC. Finally, understanding the molecular mechanism(s) by which chemokines orchestrate the progression from a physiologic inflammatory condition to pathologic inflammation and neoplasia in the human colon will lead to development of novel therapeutic approaches for prevention and amelioration of IBD and CRC. Thus, it is critical that we evaluate whether chemokine-neutralizing antibodies or receptor antagonists of tumor promoting chemokines, or alternatively agonists of tumor suppressing chemokine receptors, can serve as drug targets for prevention and treatment of IBD and CRC.

\section{Acknowledgments}

This work is supported, in part, from the National Institutes of Health Grants RO1CA 34590-27(AR), a VA Research Career Scientist Award (AR), RO1DK 62112, P01-CA-77839, R37-DK47297, and P30 DK-58404 (RND). RND (R37DK47297) is recipient of an NIH MERIT award.

\section{References}

Papers of particular interest, published within the period of review, have been highlighted as:

* of specific interest; ** of outstanding interest

1. Kuper H, Adami HO, Trichopoulos D. Infections as a major preventable cause of human cancer. J Intern Med 2000;248:171-183. [PubMed: 10971784]

2. Smalley WE, DuBois RN. Colorectal cancer and nonsteroidal anti-inflammatory drugs. Adv Pharmacol 1997;39:1-20. [PubMed: 9160111]

3. Lewis JD, Deren JJ, Lichtenstein GR. Cancer risk in patients with inflammatory bowel disease. Gastroenterol Clin North Am 1999;28:459-477. x. [PubMed: 10372277]

4. Izzo AA, Camilleri M. Emerging role of cannabinoids in gastrointestinal and liver diseases: basic and clinical aspects. Gut 2008;57:1140-1155. [PubMed: 18397936]

5. Harrington LE, Mangan PR, Weaver CT. Expanding the effector CD4 T-cell repertoire: the Th17 lineage. Curr Opin Immunol 2006;18:349-356. [PubMed: 16616472]

6. Steinman L. A brief history of $\mathrm{T}(\mathrm{H}) 17$, the first major revision in the $\mathrm{T}(\mathrm{H}) 1 / \mathrm{T}(\mathrm{H}) 2$ hypothesis of $\mathrm{T}$ cell-mediated tissue damage. Nat Med 2007;13:139-145. [PubMed: 17290272] 
7. Neuman MG. Immune dysfunction in inflammatory bowel disease. Transl Res 2007;149:173-186. [PubMed: 17383591]

8. Strober W, Fuss I, Mannon P. The fundamental basis of inflammatory bowel disease. J Clin Invest 2007;117:514-521. [PubMed: 17332878]

9. Sands BE. Inflammatory bowel disease: past, present, and future. J Gastroenterol 2007;42:16-25. [PubMed: 17322989]

10. Mahida YR. The key role of macrophages in the immunopathogenesis of inflammatory bowel disease. Inflamm Bowel Dis 2000;6:21-33. [PubMed: 10701146]

11. Gijsbers K, Geboes K, Van Damme J. Chemokines in gastrointestinal disorders. Curr Drug Targets 2006;7:47-64. [PubMed: 16454699]

12. Danese S, Gasbarrini A. Chemokines in inflammatory bowel disease. J Clin Pathol 2005;58:10251027. [PubMed: 16189145]

13. Alzoghaibi MA, Al-Mofleh IA, Al-Jebreen AM. Neutrophil chemokines GCP-2 and GRO-alpha in patients with inflammatory bowel disease. J Dig Dis 2008;9:144-148. [PubMed: 18956592]* Data indicate that serum levels of GROalpha (CXCL1) may serve as a biomarker for IBD.

14. Ina K, Kusugami K, Yamaguchi T, Imada A, Hosokawa T, Ohsuga M, Shinoda M, Ando T, Ito K, Yokoyama Y. Mucosal interleukin-8 is involved in neutrophil migration and binding to extracellular matrix in inflammatory bowel disease. Am J Gastroenterol 1997;92:1342-1346. [PubMed: 9260803]

15. Keates S, Keates AC, Mizoguchi E, Bhan A, Kelly CP. Enterocytes are the primary source of the chemokine ENA-78 in normal colon and ulcerative colitis. Am J Physiol 1997;273:G75-82. [PubMed: 9252512]

16. Z'Graggen K, Walz A, Mazzucchelli L, Strieter RM, Mueller C. The C-X-C chemokine ENA-78 is preferentially expressed in intestinal epithelium in inflammatory bowel disease. Gastroenterology 1997;113:808-816. [PubMed: 9287972]

17. Gijsbers K, Van Assche G, Joossens S, Struyf S, Proost P, Rutgeerts P, Geboes K, Van Damme J. CXCR1-binding chemokines in inflammatory bowel diseases: down-regulated IL-8/CXCL8 production by leukocytes in Crohn's disease and selective GCP-2/CXCL6 expression in inflamed intestinal tissue. Eur J Immunol 2004;34:1992-2000. [PubMed: 15214047]

18. Mitsuyama K, Tsuruta O, Tomiyasu N, Takaki K, Suzuki A, Masuda J, Yamasaki H, Toyonaga A, Sata M. Increased circulating concentrations of growth-related oncogene (GRO)-alpha in patients with inflammatory bowel disease. Dig Dis Sci 2006;51:173-177. [PubMed: 16416232]

19. Benelli R, Morini M, Carrozzino F, Ferrari N, Minghelli S, Santi L, Cassatella M, Noonan DM, Albini A. Neutrophils as a key cellular target for angiostatin: implications for regulation of angiogenesis and inflammation. Faseb J 2002;16:267-269. [PubMed: 11772950]

20. Thapa D, Lee JS, Park SY, Bae YH, Bae SK, Kwon JB, Kim KJ, Kwak MK, Park YJ, Choi HG, et al. Clotrimazole ameliorates intestinal inflammation and abnormal angiogenesis by inhibiting interleukin-8 expression through a nuclear factor-kappaB-dependent manner. J Pharmacol Exp Ther 2008;327:353-364. [PubMed: 18728240]* This in vivo study established an important role of IL-8 (CXCL8) in inflammation-induced angiogenesis.

21. Chakravarti A, Rusu D, Flamand N, Borgeat P, Poubelle PE. Reprogramming of a subpopulation of human blood neutrophils by prolonged exposure to cytokines. Lab Invest. 2009

22. Hawinkels LJ, Zuidwijk K, Verspaget HW, de Jonge-Muller ES, van Duijn W, Ferreira V, Fontijn RD, David G, Hommes DW, Lamers CB, et al. VEGF release by MMP-9 mediated heparan sulphate cleavage induces colorectal cancer angiogenesis. Eur J Cancer 2008;44:1904-1913. [PubMed: 18691882]

23. Romagnani S. Induction of TH1 and TH2 responses: a key role for the 'natural' immune response? Immunol Today 1992;13:379-381. [PubMed: 1418371]

24. Singh UP, Venkataraman C, Singh R, Lillard JW Jr. CXCR3 axis: role in inflammatory bowel disease and its therapeutic implication. Endocr Metab Immune Disord Drug Targets 2007;7:111-123. [PubMed: 17584151]** Recent review of the role of CXCR3 axis in IBD.

25. Singh UP, Singh S, Taub DD, Lillard JW Jr. Inhibition of IFN-gamma-inducible protein-10 abrogates colitis in IL-10-/- mice. J Immunol 2003;171:1401-1406. [PubMed: 12874231] 
26. Seiderer J, Dambacher J, Leistner D, Tillack C, Glas J, Niess JH, Pfennig S, Jurgens M, MullerMyhsok B, Goke B, et al. Genotype-phenotype analysis of the CXCL16 p.Ala181Val polymorphism in inflammatory bowel disease. Clin Immunol 2008;127:49-55. [PubMed: 18248772]

27. Mikami S, Nakase H, Yamamoto S, Takeda Y, Yoshino T, Kasahara K, Ueno S, Uza N, Oishi S, Fujii N, et al. Blockade of CXCL12/CXCR4 axis ameliorates murine experimental colitis. J Pharmacol Exp Ther 2008;327:383-392. [PubMed: 18716065]* This paper provides the first in vivo demonstration that the CXCL12/CXCR4 signals are involved in IBD progression.

28. Zhong W, Kolls JK, Chen H, McAllister F, Oliver PD, Zhang Z. Chemokines orchestrate leukocyte trafficking in inflammatory bowel disease. Front Biosci 2008;13:1654-1664. [PubMed: 17981657]

29. Khan WI, Motomura Y, Wang H, El-Sharkawy RT, Verdu EF, Verma-Gandhu M, Rollins BJ, Collins SM. Critical role of MCP-1 in the pathogenesis of experimental colitis in the context of immune and enterochromaffin cells. Am J Physiol Gastrointest Liver Physiol 2006;291:G803-811. [PubMed: 16728728]

30. Andres PG, Beck PL, Mizoguchi E, Mizoguchi A, Bhan AK, Dawson T, Kuziel WA, Maeda N, MacDermott RP, Podolsky DK, et al. Mice with a selective deletion of the CC chemokine receptors 5 or 2 are protected from dextran sodium sulfate-mediated colitis: lack of CC chemokine receptor 5 expression results in a NK1.1+ lymphocyte-associated Th2-type immune response in the intestine. J Immunol 2000;164:6303-6312. [PubMed: 10843684]

31. Tokuyama H, Ueha S, Kurachi M, Matsushima K, Moriyasu F, Blumberg RS, Kakimi K. The simultaneous blockade of chemokine receptors CCR2, CCR5 and CXCR3 by a non-peptide chemokine receptor antagonist protects mice from dextran sodium sulfate-mediated colitis. Int Immunol 2005;17:1023-1034. [PubMed: 16000328]

32. Lugering A, Kucharzik T, Soler D, Picarella D, Hudson JT 3rd, Williams IR. Lymphoid precursors in intestinal cryptopatches express CCR6 and undergo dysregulated development in the absence of CCR6. J Immunol 2003;171:2208-2215. [PubMed: 12928364]

33. Rivera-Nieves J, Ho J, Bamias G, Ivashkina N, Ley K, Oppermann M, Cominelli F. Antibody blockade of CCL25/CCR9 ameliorates early but not late chronic murine ileitis. Gastroenterology 2006;131:1518-1529. [PubMed: 17101325]

34. Yuan Q, Bromley SK, Means TK, Jones KJ, Hayashi F, Bhan AK, Luster AD. CCR4-dependent regulatory T cell function in inflammatory bowel disease. J Exp Med 2007;204:1327-1334. [PubMed: 17548518]** Animal studies in this paper show that CCR4-deficient T reg cells fail to suppress the development of colitis, suggesting that CCR4 plays a key role in IBD.

35. Schneider MA, Meingassner JG, Lipp M, Moore HD, Rot A. CCR7 is required for the in vivo function of CD4+ CD25+ regulatory T cells. J Exp Med 2007;204:735-745. [PubMed: 17371928]** This paper provides genetic evidence that CCR7 negative $\mathrm{T}$ reg cells are less able to prevent the development of IBD than CCR7 positive T reg cells.

36. Kaser A, Tilg H. Novel therapeutic targets in the treatment of IBD. Expert Opin Ther Targets 2008;12:553-563. [PubMed: 18410239]

37. Rothenberg ME, Hogan SP. The eosinophil. Annu Rev Immunol 2006;24:147-174. [PubMed: 16551246]

38. Ahrens R, Waddell A, Seidu L, Blanchard C, Carey R, Forbes E, Lampinen M, Wilson T, Cohen E, Stringer K, et al. Intestinal macrophage/epithelial cell-derived CCL11/eotaxin-1 mediates eosinophil recruitment and function in pediatric ulcerative colitis. J Immunol 2008;181:7390-7399. [PubMed: $18981162]^{* *}$ In vivo experiments demonstrate that eosinophil recruitment is required for IBD and depends on CCL11.

39. Brand S, Olszak T, Beigel F, Diebold J, Otte JM, Eichhorst ST, Goke B, Dambacher J. Cell differentiation dependent expressed CCR6 mediates ERK-1/2, SAPK/JNK, and Akt signaling resulting in proliferation and migration of colorectal cancer cells. J Cell Biochem 2006;97:709-723. [PubMed: 16215992]

40. Varona R, Cadenas V, Flores J, Martinez AC, Marquez G. CCR6 has a non-redundant role in the development of inflammatory bowel disease. Eur J Immunol 2003;33:2937-2946. [PubMed: 14515278]

41. Balkwill F. Cancer and the chemokine network. Nat Rev Cancer 2004;4:540-550. [PubMed: 15229479] 
42. Coussens LM, Werb Z. Inflammation and cancer. Nature 2002;420:860-867. [PubMed: 12490959]

43. Baier PK, Eggstein S, Wolff-Vorbeck G, Baumgartner U, Hopt UT. Chemokines in human colorectal carcinoma. Anticancer Res 2005;25:3581-3584. [PubMed: 16101183]

44. Speetjens FM, Kuppen PJ, Sandel MH, Menon AG, Burg D, van de Velde CJ, Tollenaar RA, de Bont HJ, Nagelkerke JF. Disrupted expression of CXCL5 in colorectal cancer is associated with rapid tumor formation in rats and poor prognosis in patients. Clin Cancer Res 2008;14:2276-2284. [PubMed: 18413816]

45. Rubie C, Frick VO, Wagner M, Schuld J, Graber S, Brittner B, Bohle RM, Schilling MK. ELR+ CXC chemokine expression in benign and malignant colorectal conditions. BMC Cancer 2008;8:178. [PubMed: 18578857]* Clinical data from this paper show a correlation between CXCL1 and CXCL5 expression and the status of CRC.

46. Jiang W, Li X, Rao S, Wang L, Du L, Li C, Wu C, Wang H, Wang Y, Yang B. Constructing diseasespecific gene networks using pair-wise relevance metric: application to colon cancer identifies interleukin 8, desmin and enolase 1 as the central elements. BMC Syst Biol 2008;2:72. [PubMed: 18691435]

47. Kuilman T, Michaloglou C, Vredeveld LC, Douma S, van Doorn R, Desmet CJ, Aarden LA, Mooi WJ, Peeper DS. Oncogene-induced senescence relayed by an interleukin-dependent inflammatory network. Cell 2008;133:1019-1031. [PubMed: 18555778]

48. Watanabe H, Miki C, Okugawa Y, Toiyama Y, Inoue Y, Kusunoki M. Decreased expression of monocyte chemoattractant protein-1 predicts poor prognosis following curative resection of colorectal cancer. Dis Colon Rectum 2008;51:1800-1805. [PubMed: 18633677]

49. Mumtaz M, Wagsater D, Lofgren S, Hugander A, Zar N, Dimberg J. Decreased expression of the chemokine CCL21 in human colorectal adenocarcinomas. Oncol Rep 2009;21:153-158. [PubMed: 19082456]

50. Dimberg J, Hugander A, Wagsater D. Protein expression of the chemokine, CCL28, in human colorectal cancer. Int J Oncol 2006;28:315-319. [PubMed: 16391784]

51. Allavena P, Sica A, Garlanda C, Mantovani A. The Yin-Yang of tumor-associated macrophages in neoplastic progression and immune surveillance. Immunol Rev 2008;222:155-161. [PubMed: 18364000]** Excellent review covering the role of macrophages in tumor formation and progression.

52. Tsuchiyama T, Nakamoto Y, Sakai Y, Mukaida N, Kaneko S. Optimal amount of monocyte chemoattractant protein-1 enhances antitumor effects of suicide gene therapy against hepatocellular carcinoma by M1 macrophage activation. Cancer Sci 2008;99:2075-2082. [PubMed: 19016769]

53. Kim J, Takeuchi H, Lam ST, Turner RR, Wang HJ, Kuo C, Foshag L, Bilchik AJ, Hoon DS. Chemokine receptor CXCR4 expression in colorectal cancer patients increases the risk for recurrence and for poor survival. J Clin Oncol 2005;23:2744-2753. [PubMed: 15837989]

54. Schimanski CC, Schwald S, Simiantonaki N, Jayasinghe C, Gonner U, Wilsberg V, Junginger T, Berger MR, Galle PR, Moehler M. Effect of chemokine receptors CXCR4 and CCR7 on the metastatic behavior of human colorectal cancer. Clin Cancer Res 2005;11:1743-1750. [PubMed: 15755995]

55. Gunther K, Leier J, Henning G, Dimmler A, Weissbach R, Hohenberger W, Forster R. Prediction of lymph node metastasis in colorectal carcinoma by expressionof chemokine receptor CCR7. Int $\mathbf{J}$ Cancer 2005;116:726-733. [PubMed: 15828050]

56. Kawada K, Hosogi H, Sonoshita M, Sakashita H, Manabe T, Shimahara Y, Sakai Y, Takabayashi A, Oshima M, Taketo MM. Chemokine receptor CXCR3 promotes colon cancer metastasis to lymph nodes. Oncogene 2007;26:4679-4688. [PubMed: 17297455]* The first report shows an involvement of CXCR3 in colon tumor metastasis.

57. Kollmar O, Scheuer C, Menger MD, Schilling MK. Macrophage inflammatory protein-2 promotes angiogenesis, cell migration, and tumor growth in hepatic metastasis. Ann Surg Oncol 2006;13:263275. [PubMed: 16424980]

58. Yoshitake N, Fukui H, Yamagishi H, Sekikawa A, Fujii S, Tomita S, Ichikawa K, Imura J, Hiraishi $\mathrm{H}$, Fujimori T. Expression of SDF-1 alpha and nuclear CXCR4 predicts lymph node metastasis in colorectal cancer. Br J Cancer 2008;98:1682-1689. [PubMed: 18443596]* Clinical data are provided in this paper showing that CXCL12 and CXCR4 may serve as biomarkers for CRC metastasis. 
59. Lurje G, Zhang W, Schultheis AM, Yang D, Groshen S, Hendifar AE, Husain H, Gordon MA, Nagashima F, Chang HM, et al. Polymorphisms in VEGF and IL-8 predict tumor recurrence in stage III colon cancer. Ann Oncol 2008;19:1734-1741. [PubMed: 18550579]* Clinical data in this paper show a relation between polymorphism of CXCL8 and risk of tumor recurrence of CRC patients treated with adjuvant chemotherapy.

60. Ohta M, Tanaka F, Yamaguchi H, Sadanaga N, Inoue H, Mori M. The high expression of Fractalkine results in a better prognosis for colorectal cancer patients. Int J Oncol 2005;26:41-47. [PubMed: 15586223]

61. Rubie C, Oliveira V, Kempf K, Wagner M, Tilton B, Rau B, Kruse B, Konig J, Schilling M. Involvement of chemokine receptor CCR6 in colorectal cancer metastasis. Tumour Biol 2006;27:166-174. [PubMed: 16641550]

62. Sturm A, Baumgart DC, d'Heureuse JH, Hotz A, Wiedenmann B, Dignass AU. CXCL8 modulates human intestinal epithelial cells through a CXCR1 dependent pathway. Cytokine 2005;29:42-48. [PubMed: 15579377]

63. Zipin-Roitman A, Meshel T, Sagi-Assif O, Shalmon B, Avivi C, Pfeffer RM, Witz IP, Ben-Baruch A. CXCL10 promotes invasion-related properties in human colorectal carcinoma cells. Cancer Res 2007;67:3396-3405. [PubMed: 17409450]

64. Li A, Varney ML, Singh RK. Constitutive expression of growth regulated oncogene (gro) in human colon carcinoma cells with different metastatic potential and its role in regulating their metastatic phenotype. Clin Exp Metastasis 2004;21:571-579. [PubMed: 15787094]

65. Bates RC, DeLeo MJ 3rd, Mercurio AM. The epithelial-mesenchymal transition of colon carcinoma involves expression of IL-8 and CXCR-1-mediated chemotaxis. Exp Cell Res 2004;299:315-324. [PubMed: 15350531]

66. Zeelenberg IS, Ruuls-Van Stalle L, Roos E. The chemokine receptor CXCR4 is required for outgrowth of colon carcinoma micrometastases. Cancer Res 2003;63:3833-3839. [PubMed: 12839981]

67. Vitale S, Cambien B, Karimdjee BF, Barthel R, Staccini P, Luci C, Breittmayer V, Anjuere F, SchmidAlliana A, Schmid-Antomarchi H. Tissue-specific differential antitumour effect of molecular forms of fractalkine in a mouse model of metastatic colon cancer. Gut 2007;56:365-372. [PubMed: 16870716]

68. Kitamura T, Taketo MM. Keeping out the bad guys: gateway to cellular target therapy. Cancer Res 2007;67:10099-10102. [PubMed: 17974948]

69. Dimberg J, Dienus O, Lofgren S, Hugander A, Wagsater D. Expression and gene polymorphisms of the chemokine CXCL5 in colorectal cancer patients. Int J Oncol 2007;31:97-102. [PubMed: 17549409]

70. Bailey C, Negus R, Morris A, Ziprin P, Goldin R, Allavena P, Peck D, Darzi A. Chemokine expression is associated with the accumulation of tumour associated macrophages (TAMs) and progression in human colorectal cancer. Clin Exp Metastasis 2007;24:121-130. [PubMed: 17390111]

71. Itoh Y, Joh T, Tanida S, Sasaki M, Kataoka H, Itoh K, Oshima T, Ogasawara N, Togawa S, Wada T, et al. IL-8 promotes cell proliferation and migration through metalloproteinase-cleavage proHBEGF in human colon carcinoma cells. Cytokine 2005;29:275-282. [PubMed: 15749028]

72. Meijer J, Ogink J, Roos E. Effect of the chemokine receptor CXCR7 on proliferation of carcinoma cells in vitro and in vivo. Br J Cancer 2008;99:1493-1501. [PubMed: 18854833]This paper addresses the controversy with regard to the functional role of CXCR7. Using two different cancer cell lines, a ligand stated to be specific for CXCR7 was shown to stimulate the growth and chemotaxis of CT26 colon carcinoma and KEP1 mammary carcinoma cells. However, when CXCR7 expression was knocked down by siRNA, there was no effect on the growth or lung metastasis of subcutaneous xenografts of these tumor cell lines.

73. Kollmar O, Junker B, Rupertus K, Menger MD, Schilling MK. Studies on MIP-2 and CXCR2 expression in a mouse model of extrahepatic colorectal metastasis. Eur J Surg Oncol 2007;33:803811. [PubMed: 17314027]

74. Meijer J, Zeelenberg IS, Sipos B, Roos E. The CXCR5 chemokine receptor is expressed by carcinoma cells and promotes growth of colon carcinoma in the liver. Cancer Res 2006;66:9576-9582.

[PubMed: 17018614] 
75. Fushimi T, O'Connor TP, Crystal RG. Adenoviral gene transfer of stromal cell-derived factor-1 to murine tumors induces the accumulation of dendritic cells and suppresses tumor growth. Cancer Res 2006;66:3513-3522. [PubMed: 16585175]

76. Nukiwa M, Andarini S, Zaini J, Xin H, Kanehira M, Suzuki T, Fukuhara T, Mizuguchi H, Hayakawa T, Saijo Y, et al. Dendritic cells modified to express fractalkine/CX3CL1 in the treatment of preexisting tumors. Eur J Immunol 2006;36:1019-1027. [PubMed: 16525992]

77. Hisada M, Yoshimoto T, Kamiya S, Magami Y, Miyaji H, Yoneto T, Tamada K, Aoki T, Koyanagi Y, Mizuguchi J. Synergistic antitumor effect by coexpression of chemokine CCL21/SLC and costimulatory molecule LIGHT. Cancer Gene Ther 2004;11:280-288. [PubMed: 15002032]

78. Kanagawa N, Niwa M, Hatanaka Y, Tani Y, Nakagawa S, Fujita T, Yamamoto A, Okada N. CCchemokine ligand 17 gene therapy induces tumor regression through augmentation of tumorinfiltrating immune cells in a murine model of preexisting CT26 colon carcinoma. Int J Cancer 2007;121:2013-2022. [PubMed: 17621629]

79. Hou JM, Zhao X, Tian L, Li G, Zhang R, Yao B, Deng HX, Yang JL, Wei YQ. Immunotherapy of tumors with recombinant adenovirus encoding macrophage inflammatory protein 3 beta induces tumor-specific immune response in immunocompetent tumor-bearing mice. Acta Pharmacol Sin 2009;30:355-363. [PubMed: 19262559]

80. Flanagan K, Glover RT, Horig H, Yang W, Kaufman HL. Local delivery of recombinant vaccinia virus expressing secondary lymphoid chemokine (SLC) results in a CD4 T-cell dependent antitumor response. Vaccine 2004;22:2894-2903. [PubMed: 15246626]

81. Ju DW, Tao Q, Cheng DS, Zhang W, Zhang M, Hamada H, Cao X. Adenovirus-mediated lymphotactin gene transfer improves therapeutic efficacy of cytosine deaminase suicide gene therapy in established murine colon carcinoma. Gene Ther 2000;7:329-338. [PubMed: 10694814]

82. Strieter RM, Burdick MD, Mestas J, Gomperts B, Keane MP, Belperio JA. Cancer CXC chemokine networks and tumour angiogenesis. Eur J Cancer 2006;42:768-778. [PubMed: 16510280]

83. Wen Y, Giardina SF, Hamming D, Greenman J, Zachariah E, Bacolod MD, Liu H, Shia J, Amenta PS, Barany F, et al. GROalpha is highly expressed in adenocarcinoma of the colon and down-regulates fibulin-1. Clin Cancer Res 2006;12:5951-5959. [PubMed: 17062666]

84. Wang D, Wang H, Brown J, Daikoku T, Ning W, Shi Q, Richmond A, Strieter R, Dey SK, DuBois RN. CXCL1 induced by prostaglandin E2 promotes angiogenesis in colorectal cancer. J Exp Med 2006;203:941-951. [PubMed: 16567391]

85. Guleng B, Tateishi K, Ohta M, Kanai F, Jazag A, Ijichi H, Tanaka Y, Washida M, Morikane K, Fukushima Y, et al. Blockade of the stromal cell-derived factor-1/CXCR4 axis attenuates in vivo tumor growth by inhibiting angiogenesis in a vascular endothelial growth factor-independent manner. Cancer Res 2005;65:5864-5871. [PubMed: 15994964]

86. Tanaka S, Tatsuguchi A, Futagami S, Gudis K, Wada K, Seo T, Mitsui K, Yonezawa M, Nagata K, Fujimori S, et al. Monocyte chemoattractant protein 1 and macrophage cyclooxygenase 2 expression in colonic adenoma. Gut 2006;55:54-61. [PubMed: 16085694]

87. Zhang R, Tian L, Chen LJ, Xiao F, Hou JM, Zhao X, Li G, Yao B, Wen YJ, Li J, et al. Combination of MIG (CXCL9) chemokine gene therapy with low-dose cisplatin improves therapeutic efficacy against murine carcinoma. Gene Ther 2006;13:1263-1271. [PubMed: 16672984]

88. Li G, Tian L, Hou JM, Ding ZY, He QM, Feng P, Wen YJ, Xiao F, Yao B, Zhang R, et al. Improved therapeutic effectiveness by combining recombinant CXC chemokine ligand 10 with Cisplatin in solid tumors. Clin Cancer Res 2005;11:4217-4224. [PubMed: 15930360] 


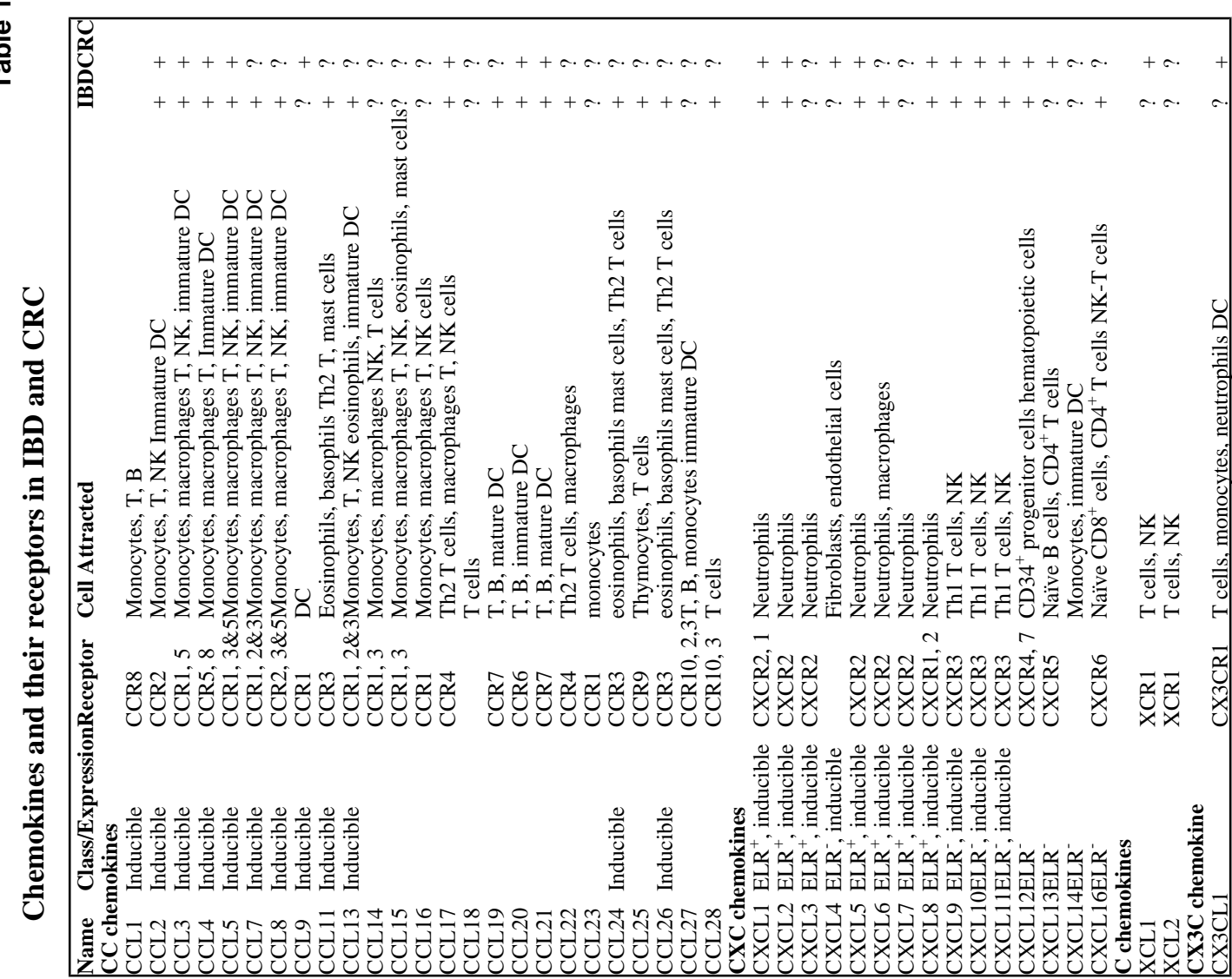

Curr Opin Pharmacol. Author manuscript; available in PMC 2010 December 1. 